Volume 9, No.1, January - February 2020

International Journal of Advanced Trends in Computer Science and Engineering

Available Online at http://www.warse.org/IJATCSE/static/pdf/file/ijatcse101912020.pdf

https://doi.org/10.30534/ijatcse/2020/101912020

\title{
A Virtual reality serious game for Language learning
}

\author{
Yassine Tazouti ${ }^{1}$, Siham Boulaknadel ${ }^{2}$, Youssef Fakhri ${ }^{3}$ \\ ${ }_{1,3}^{13}$ Ibn Tofail University, Morocco, Yassine.Tazouti@uit.ac.ma \\ ${ }^{2}$ Royal Institute of Amazigh Culture, Morocco, boulaknadel@ircam.ma
}

\begin{abstract}
At present, serious games are experiencing a growing popularity, with areas of application that extend not only to education, but also to other sectors such as the military, health and business sectors, among others. Since video games facilitate the learning of complex processes, their associated benefits have been reoriented principally to the educational, training and information processes. This paper presents second version of ImALeG [1] project known as "ImALeG VR", a Multiplatform 3D serious game that support virtual reality, whose objective is to develop and auto evaluate competencies of Amazighe language learning alphabet and vocabulary in a virtual environment. this serious game project aims to enrich an old language practiced for centuries not just in Morocco but by many African countries and which reflects a part of their identity and culture.
\end{abstract}

Key words: serious game, educational game, virtual environment, language learning, virtual reality

\section{INTRODUCTION}

Game-based learning has the potential to improve teaching and performance of Moroccan students. A recent study has revealed that serious games contribute to the enhancement of learning $[2,3,4,5]$, thus recommending its practice to support teaching. Game mechanics can be used to produce highly interactive environment that seduce the players by improving the learning contents associated to Amazighe language and enhancing the decision making by having a fast concrete and coherent feedback. Game based learning could increase the degree of attention through learning by discovery, the freedom of action and the spirit of competition.

The presented work has been developed under the research case to apply serious game for learning Amazighe vocabulary in virtual world. The aim of the study is to apply a serious hyper realistic game and interactive Non-Player Characters (NPCs) agents to improve the learning performance. Levels Mechanics of ImALeG refers to the integration of different technologies and interdisciplinary methodologies leading to accomplish this research project. The fundamental objective is to improve Tifinaghe alphabet learning, Amazighe animal names, home items names, facilitating user's immersion. ImALeG, is a serious game developed for interactively learning Amazighe language. The game uses the 3D virtual reality environment exploiting 'learn-by-doing' techniques for language acquisition. The 3D environment allows learning process personalization and enhances learner awareness of the acquired learning skills. Furthermore, it permits ubiquitous learning as well as universal access, features that aid the collection of big amounts of test data over the web and make the game excellent as a tool for comparing different teaching methodologies.

\section{SERIOUS GAMES APPLICATION}

\subsection{Military}

The first games are based on combat and fighting. For example, board games such as "Chaturanga and WeiHei" [5] a game designed for the development of battle strategies of soldiers and the appearance of Marine Doom and marine doom II in 90 [7], when the potential of the games began to be appreciated. Instead of a first-person shooter, more realistic weapons were presented and tasks that encouraged learning the appropriate sequence of attacks [8], such as preserving ammunition, cooperate effectively, giving orders and working as a squad, were included. In recent years, the United States military is exploring the use of serious games as a way to help them learn to use equipment [9], with the remotely operated weapons station.

\subsection{Health}

Serious games related to health are a field in continuous growth. These types of serious games are based on simulation and used for medical training. As a sample, in 2008, in Birmingham, young doctors were allowed to experiment and train for a variation of medical scenarios by using computerized models as if they were patients [10]. In 2012, "Graafland et al" [11] led a systematic assessment of serious games for the teaching of surgical skills and medical knowledge. In their work they presented 13 serious game to develop necessary skills for medical personnel. The conclusion of his work was that serious games can be used both to develop technical and non-technical skills in the 
surgical field. On the other hand, comparing traditional teaching and training using virtual reality and game-based tools for laparoscopic surgery indicated that the latter was less expensive, took less time and resulted in fewer medical errors than when the surgery was actually performed. As well as these, there are other games such as The Virtual Dental Implant Training Simulation, which was designed to help dentistry students in diagnosis, decision making and training protocols.

\subsection{Education}

In order to take into account games that were not originally intended for teaching and learning purposes, it is appropriate, according to a proposal by "Jenkins et al. (2009)" [12] speak of serious gaming as a usage rather than serious games as a category of games. "Breuer and Bente (2010)" [13] suggests broadening the perspective of serious-game research to include the learning potential and effects of entertainment games, and provides guidance on how to design an educational use of such titles could and where possible challenges and problems lie to use amusement games for learning purposes. There are many research projects on serious game for educational purpose. The main difference with our proposal lies in the follow-up and feedbacks, self-assessment scenarios that that the system can provide, since the tool allows the teacher to access the students results, and make recommendations that can help improve their performance.

\section{AMAZIGHE \\ LANGUAGE TEACHING APPROACHES}

Amazighe is taught most intensively in Moroccan primary schools, usually as a timetabled subject. In both independent and state sectors, Amazighe is more expected to be an improvement or extra option than a main-timetable topic. Actually, the Communicative Language Teaching (CLT) is the approach adopted by Moroccan primary school for teaching Amazighe language. It is inspired from the pedagogy of skills. The textbook designers assume that Amazigh teaching intent to master the communicative competencies, mainly oral skills based on dialogues and secondarily written skills, both in terms of expression and comprehension. Gradually, once acquired the strategies of oral, reading and writing, the learner learns cultural competence through activities, these pedagogical approaches seems to be traditional and does not apply to learners of this generation who tend to explore new information technologies that are so far unused in our educational system.

From this point we have found that serious games will be useful for Amazighe teaching as a pedagogical medium or an e-learning support that would have an importance advantage based on the motivation of learners through an emerging narrative story and transmission skills using feedbacks through learning by trial and error approach. And to stimulate interaction we integrate an NPC to present the appropriate aids for each learning situation to achieve goals and accomplish missions.

\section{IMALEG GAME DESCRIPTION}

The learner is represented as an avatar and can navigate freely and interact with the virtual world by touching, moving or communicating with NPCs which contains a finite number of states. The first UI layout take the learner to fill a registration form corresponding to his age, level of education, native language and sex, user name and password, to define its profile and to store theses information in an external database for later usage. Once it's done the learner arrives at cinematic scenario to make the learner lives within the game scenario before starting the first level.

The First level of ImALeG for learning Amazighe alphabet called Tifinagh Forest. It consists on a forest with a perspective design view where Tifinagh alphabet is hiding. the player has as a main quest to find these alphabets with the help of an NPC character called Mohamed controlled by AI behavior and use an A start algorithm for the pathfinding and a finite state machine behavior to track the player movement in the 3D environment and give him instruction and information about each alphabet in the scene (fig.1). The player can identify the position of an alphabet by using a Map of the game environment that indicate the position and the direction of each Tifinaghe alphabets. each $3 \mathrm{D}$ element in the game have being previously modelled, designed, mesh rendered and animated through 3D modeling and animating tools then placed at the 3D environment, within physics laws are applied such as gravitational intensity, wind control, light intensity controlling, collision laws are applied to our 3D environment.

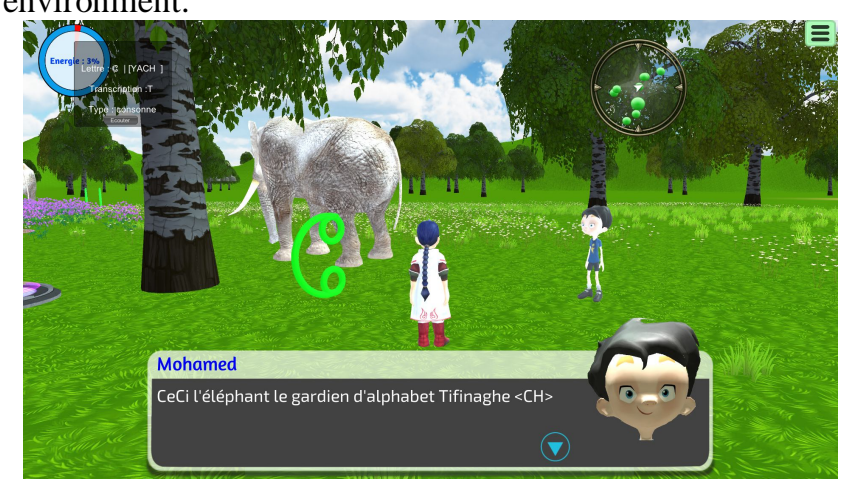

Figure 1: forest Tifinaghe Learning Level

The second level consist on learning Amazighe animal names (Fig.2)in which the player can communicate with other animal presented in the scene, these animals are moving continuedly in a specific path the player can find each animal trough the map that identify the position of each animal, the assessment mode is activated when the player learn and communicate with all animals the player must identify the animal corresponding to his name. If the player succeeds, he will be teleported to home level in which the player can 
interact with all object in home and learn rooms items vocabulary (Fig.3).

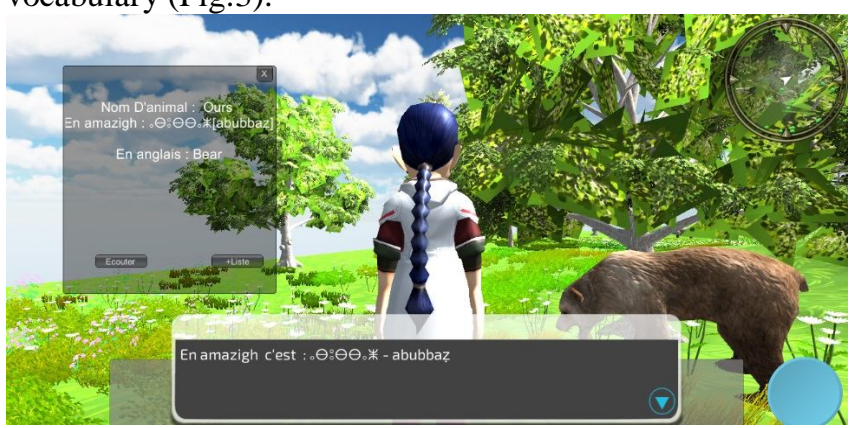

Figure 2: Animal Learning Level

The use of the 3D environment designed in unity game engine allows ImALeG to provide a huge number of game mechanics and an immersive learning scenario in each level. The learning process is adapted to learner needs and language proficiency. In each game session, the learner decides the learning content by touching specific alphabets and the type of activity he prefers to train. During a game session, the player movement, interaction, game objects clicks, health bar data; each learning interaction in system are saved to an external database through a tracking system.

Learner information can be extracted every time that the learner login. The educational goal of ImALeG is to facilitate the acquisition of Amazighe language. Currently, it can be viewed as an interactive virtual world providing the learner a new perspective tool.

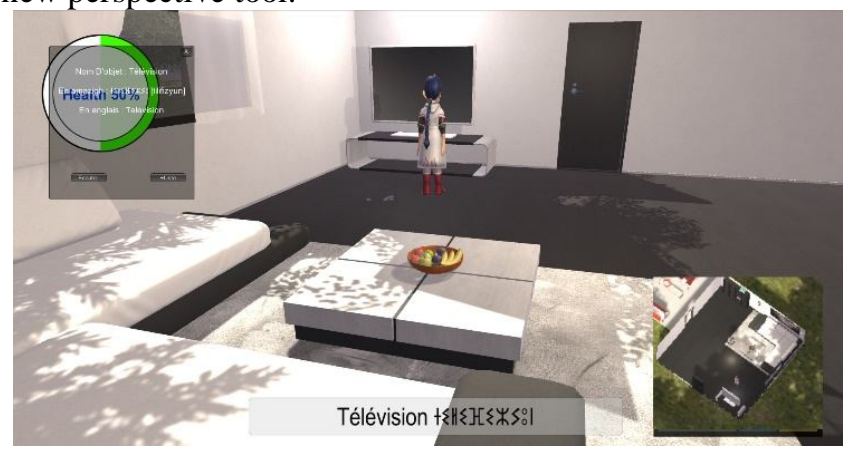

Figure 3: Home items Learning Level

Infront of using a scoring system we used health bar to fill during the learning process then he will have the necessary energy that gives the right to be teleported to another level. In this case, we used abilities in front of using scores and badges to increase more immersion process. The use of score and badges refers to serious class practices, if we use a scoring system, we risk making our game more and more serious. An evaluation system has been designed to evaluate the player learning activities at the end of each level and decide whether the learning skills have been acquired or not to move on to the next level.

\section{CONCLUSION}

ImALeG is a young concept that is constantly being improved and developed for his second version both in terms of content and technology. In its current design, the concept reflects above all the expertise of its inventors and already taken feedback from participants. In order to make serious game sustainable and to give our Moroccan school gamified courses of Amazigh, we still lack a component for the automated evaluation of user behavior. Such a component would allow us to capture long-term user behavior and identify positive and negative trends. In addition, it allows you to measure effects through changes in the course or gamification design. The insights gained can then be used as evidence to improve the course format and learning material.

\section{REFERENCES}

1. Tazouti, Y., Boulaknadel, S., \& Fakhri, Y. (2019). ImALeG: A Serious Game for Amazigh Language Learning. International Journal of Emerging Technologies in Learning (iJET), 14(18), 28-38. https://doi.org/10.3991/ijet.v14i18.10854

2. Pavlas, D., Bedwell, W., Wooten, S. R., Heyne, K., \& Salas, E. (2009, October). Investigating The Attributes In Serious Games That Contribute To Learning. In Proceedings Of The Human Factors And Ergonomics Society Annual Meeting (Vol. 53, No. 27, Pp. 1999-2003). Sage Ca: Los Angeles, Ca: Sage Publications.

3. Medema, Wietske, Furber, Alison, Adamowski, Jan, Et Al.Exploring The Potential Impact Of Serious Games On Social Learning And Stakeholder Collaborations For Transboundary Watershed Management of The St. Lawrence River Basin. Water, 2016, Vol. 8, No 5, P. 175.

4. Bottino, Rosa Maria, Ott, Michela, Et Tavella, Mauro. Serious Gaming At School: Reflections On Students' Performance, Engagement And Motivation. International Journal Of Game-Based Learning (Ijgbl), 2014, Vol. 4, No 1, P. 21-36.

5. Zhang, Yongjun, Song, Hongwen, Liu, Xiaoming, Et Al.Language Learning Enhanced By Massive Multiple Online Role-Playing Games (Mmorpgs) And The Underlying Behavioral And Neural Mechanisms. Frontiers In Human Neuroscience, 2017, Vol. 11, P. 95.

6. Gilliom, M. Eugene. Trends In Simulation. The High School Journal, 1974, Vol. 57, No 7, P. 265-272.

7. Riddell, Rob. Doom Goes To War The Marines Are Looking For A Few Good Games. Wired-San Francisco-, 1997, Vol. 5, P. 114-115.

8. Breuer, Johannes, Festl, Ruth, Et Quandt, Thorsten. In The Army Now-Narrative Elements And Realism In Military First-Person Shooters. In : Digra Conference. 2011.

9. Bonk, Curtis J. Et Dennen, Vanessa P. Massive Multiplayer Online Gaming: A Research Framework For Military Training And Education. Indiana Univ At Bloomington, 2005.

10. Robinson, Stewart, Radnor, Zoe J., Burgess, Nicola, Et Al. Simlean: Utilising Simulation In The Implementation Of Lean In Healthcare. European Journal Of Operational Research, 2012, Vol. 219, No 1, P. 188-197.

11. Graafland, Maurits, Schraagen, Jan M., Et Schijven, Marlies P. Systematic Review Of Serious Games For Medical Education And Surgical Skills Training. British Journal Of Surgery, 2012, Vol. 99, No 10, P. 1322-1330. https://doi.org/10.1002/bjs.8819 
12. Jenkins, Henry. Confronting The Challenges Of Participatory Culture: Media Education For The 21st Century. Mit Press, 2009.

13. Breuer, Johannes Et Bente, Gary. Why So Serious? On The Relation Of Serious Games And Learning. Journal For Computer Game Culture, 2010, Vol. 4, P. 7-24.

14. Omar ELYOUSSOUFI ATTOU, Said EL GANICH, Ilham TAOUAF, Moha AROUCH and Badia OULHADJ

15. Emma Nuraihan Mior Ibrahim and Suhaida Juhari. A Preliminary Study on 3600 Immersive Virtual Reality (IVR) vs Non - Immersive Virtual Reality (N-IVR) of Event Marketing. International Journal of Advanced Trends in Computer Science and Engineering. Volume 8, No.1.6, pp. 9-13,2019.

https://doi.org/10.30534/ijatcse/2019/0281.62019

16. Ryan Macdonell Andrias and Mohd Shahrizal Sunar. User/Player Type in Gamification. International Journal of Advanced Trends in Computer Science and Engineering. Volume 8, No.1.6, pp. 89 - 94, 2019.

https://doi.org/10.30534/ijatcse/2019/1481.62019 